\title{
Development of the Choroid and Related Structures*
}

\author{
K. SELLHEYER \\ Bonn, West Germany
}

\begin{abstract}
Summary
The development of the choriocapillaris and the choroid is described using light and electron microscopy. Up to the seventh week after conception, the endothelium of the choriocapillaris is thick and contains many cytoplasmic vesicles. By the ninth week the endothelium flattens and becomes vesiculated. Fenestrations are found as early as the seventh week, whereas the continuous basement membrane is only observed at the ninth week. The first choroidal arterioles and venules can be seen during the fifteenth week and the arteries and veins become distinguishable at the twenty-second week. Haller's and Sattler's layers are both venous and arterial at the time of their first appearance.
\end{abstract}

Ultrastructural studies on the normal anatomy of the human eye ${ }^{1,2}$ and the chorioretinal border tissues ${ }^{3}$ were conducted extensively in the sixties and seventies. Thus, investigation of mature ocular structures by conventional electron microscopy should only be undertaken in combination with other, more modern morphological techniques, e.g. immunohistochemistry or in situ hybridisation.

In this paper, fine structural data are given of the developing human choroid and choriocapillaris. The studies were done on eyes from human embryos and fetuses obtained through legal abortions. The age of the embryos (up to week 13) was determined by measuring the length of the tibia, femur, humerous, or radius ${ }^{4}$, enabling the ages for this period to be given as fractions of weeks. The ages of the later gestational periods was determined by ultrasonographic measurement of the biparietal diameter, and the specification of these ages refer to weeks after conception.

\section{Choriocapillaris}

The choriocapillaris starts to differentiate simultaneously with the development of the retinal pigment epithelium during the fourth and fifth week. Thus at the beginning of the sixth week, the embryonic human eye is already completely invested with a primitive capillary layer (Fig. 1). From then on, a continuous maturation process can be observed up to the end of the first trimester, when the choriocapillaris takes on an adult-like appearance.

Up to the seventh week (Fig. 4), vessel lumina can be found which are still slit-like or have the diameter of one erythroblast only. In these earlier weeks, the endothelial lining characteristically appears quite thick in comparison to its later development (Fig. 5). This thickness of the endothelium in the earlier weeks is correlated by a higher number of intracellular vesicles than is seen at later ages (Fig. 6). During the process of endothelial flattening between weeks seven and thirteen, this vesiculation seems to play an important

* Dedicated to: Prof. Dr. M. Spitznas, Bonn, my teacher in electron microscopy.

From: Alfried-Krupp-Labor, Universitäts-Augenklinik, Sigmund-Freud-Str. 25, D-5300 Bonn 1, West Germany.

Correspondence to: Dr. K. Sellheyer, Division of Dermatopathology, New York University Medical Center, Suite 77, 530 First Avenue, New York, NY 10016, USA. 


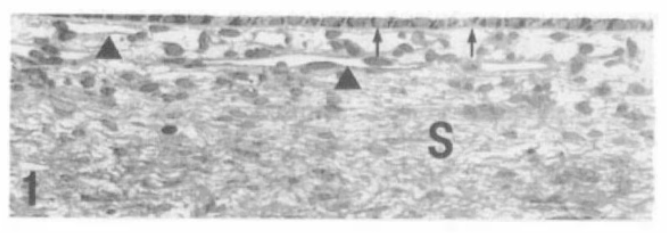

Fig. 1. Week 12. Survey of the outer coat of the eye. Up to this week the choroidal layer consists only of capillaries. Arrows: retinal pigment epithelium. S. sclera. $(\times 40)$

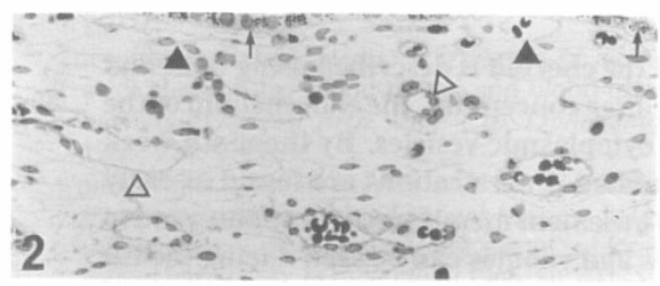

Fig. 2. Week 15. Arterioles and venule (hollow arrowheads) can be distinguished at the outer aspect of the choriocapillaris (arrowheads). Arrows: retinal pigment epithelium. $(\times 40)$

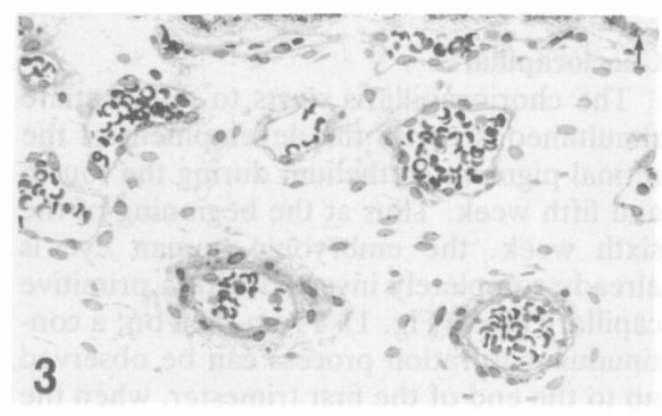

Fig. 3. Week 22. The choroidal vascular layer has reached an adult appearance. Arrow: retinal pigment epithelium. $(\times 40)$

function, comparable to that presumed for cerebral capillarogenesis during development of the adenohypophysis ${ }^{5}$ or of the cerebral cortex $^{6}$. Also, it is possible that in these earlier weeks the vesicles transport membrane material to the plasmalemmata of the endothelial cells, thereby producing an enlargement of the vascular surface, as observed in later ages.

As the endothelium flattens, fenestrations become observable. While they can first be seen during the seventh week, they become more numerous during the ninth week, which is in parallel to the decrease in the number of endothelial vesicles and the enlargement of the vascular lumen. The fenestrations are found mostly facing Bruch's membrane. Our observations contrast with those published by Mund et al., ${ }^{7}$, who stated that fenestrae are not consistently demonstrated up to week 12 , but can already be seen at this age.

Parallel to the increase in number of fenestrae, the basement membrane takes on a mature appearance. Although organized only as tiny tufts up to the seventh week, a wellestablished, continuous basement membrane develops by the beginning of the ninth week. The basement membrane material is most probably synthesized by the endothelial cells, although the possibility cannot be ruled out that the developing pericytes may also play a role in this process.

Although rarely seen, pericytes can be detected as early as the sixth week. These have the same ultrastructural appearance as the surrounding fibroblast-like cells of the periocular mesenchyme. In agreement with Ozanics et al. ${ }^{8}$ we conclude that pericytes differentiate from the mesenchymal or fibroblast-like element of the adjacent stroma.

Four out of five layers of Bruch's membrane can already be distinguished as being continuous during the ninth week (Fig. 7). Only the central, elastic layer is not fully developed even in the 13th week (Fig. 5). Fibroblasts can be distinguished in the region of Bruch's membrane, most probably contributing to the production of this membrane.

Since up to the fourth gestational month no larger vessels are observable from which the choriocapillaris could originate, it is quite reasonable to assume that the capillary network surrounding the retinal pigment epithelium derives from differentiating periocular mesenchymal cells. Development of the choroid begins during the second trimester.

\section{Choroid}

The choriodal vasculature consists solely of a choriocapillaris even into the 12th week (Fig. 1). Arterioles can be distinguished only in the region of the scleral condensation adjacent to the optic nerve entrance (Fig. 8). One can speculate that these represent a beginning stage of the Haller-Zinn circle.

Development of the choroid becomes more 


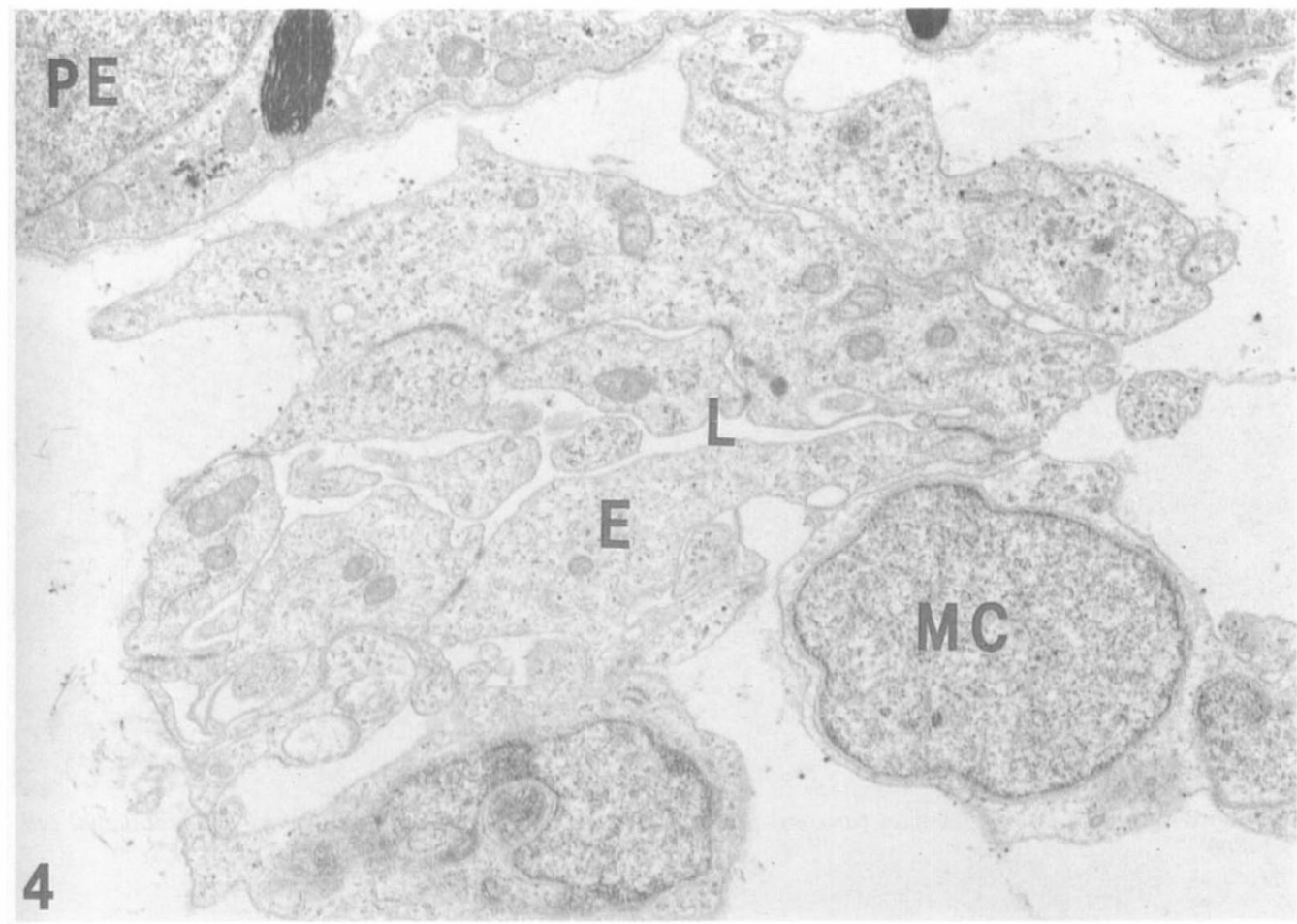

Fig. 4. Week 6.5. The primitive capillary only exhibits a slit-like lumen (L). E, endothelial cell; MC, periocular mesencymal cell; PE, retinal pigment epithelium $(\times 12200)$

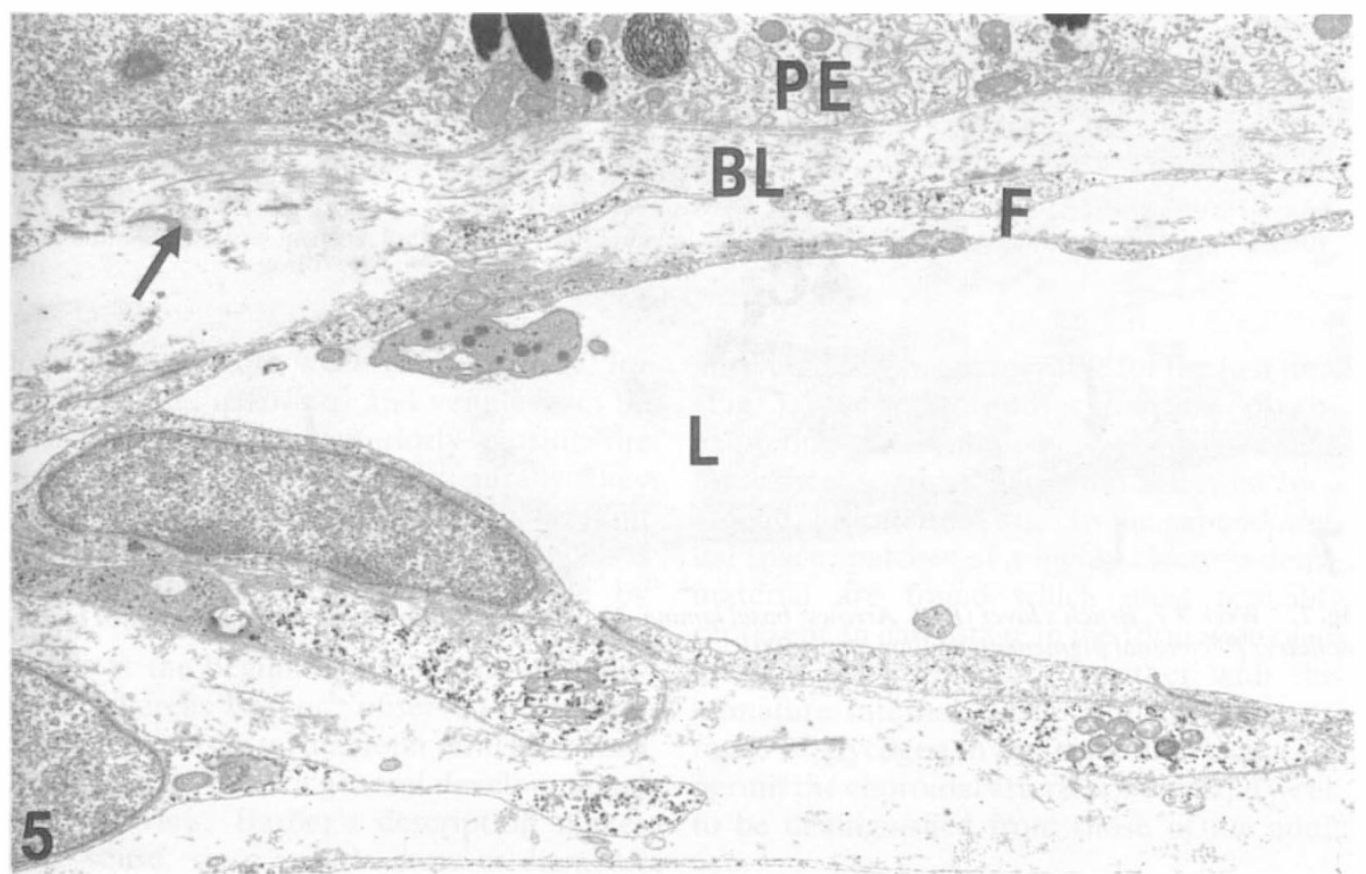

Fig. 5. Week 13. The vessel lumen $(L)$ is enlarged. Arrow: elastin. BF, Bruch's layer with fibroblastic process $(F)$; $P E$, retinal pigment epithelium. $(\times 5500)$ 


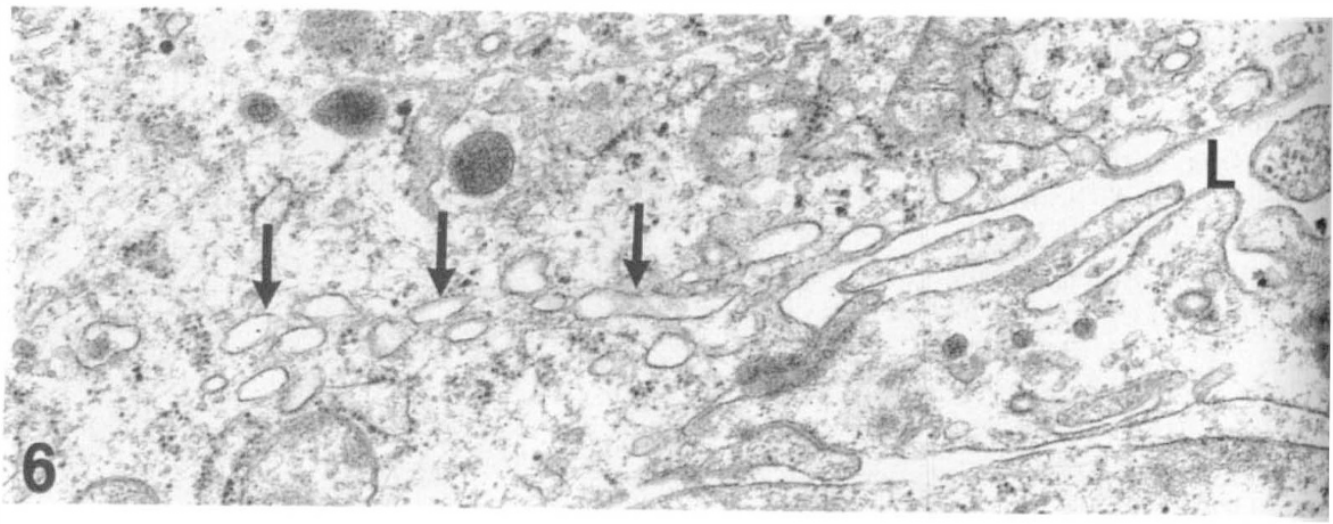

Fig. 6. Week 6.5. Chain of vesicles (arrows) directed towards the primitive lumen $(L)$ of the endothelial cell $(\times 24800)$

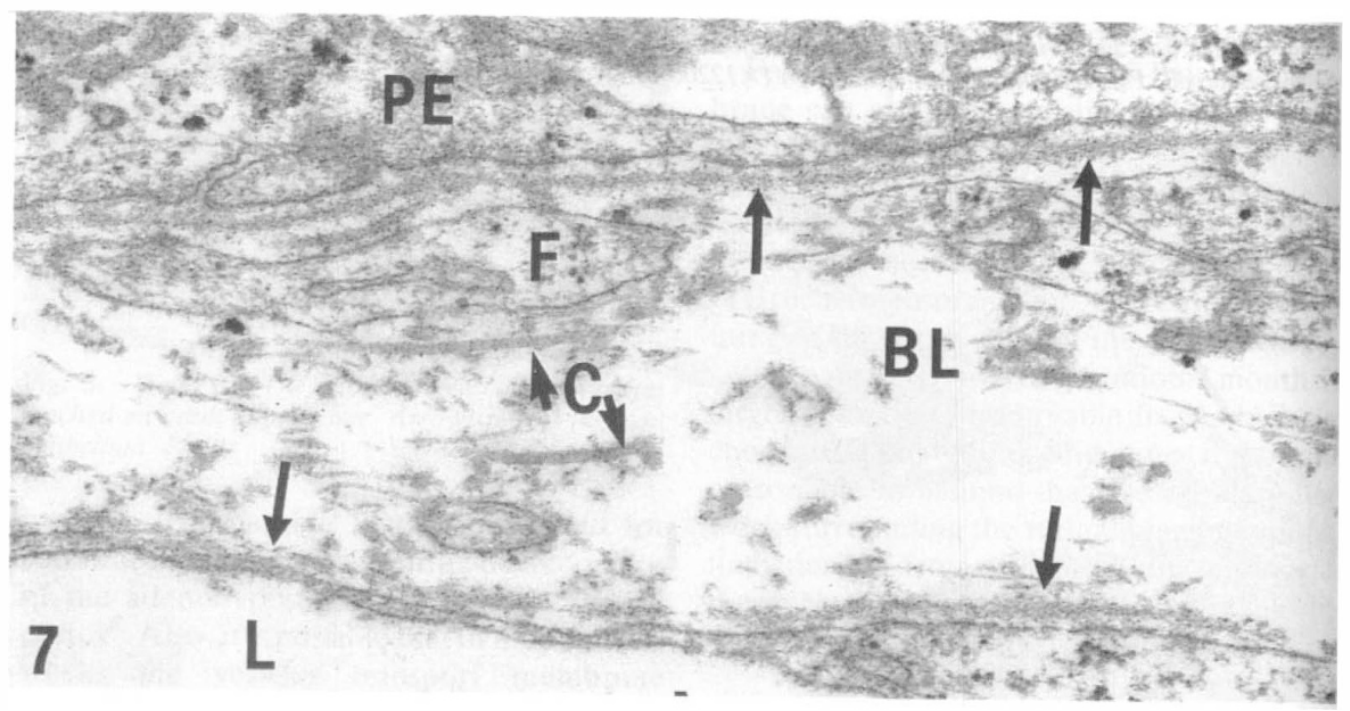

Fig. 7. Week 9.7. Bruch's layer (BL). Arrows: basal lamina. C, collagen; F, fibroblastic process; $L$, lumen of the capillary; PE, retinal pigment epithelium. $(\times 36500)$ 


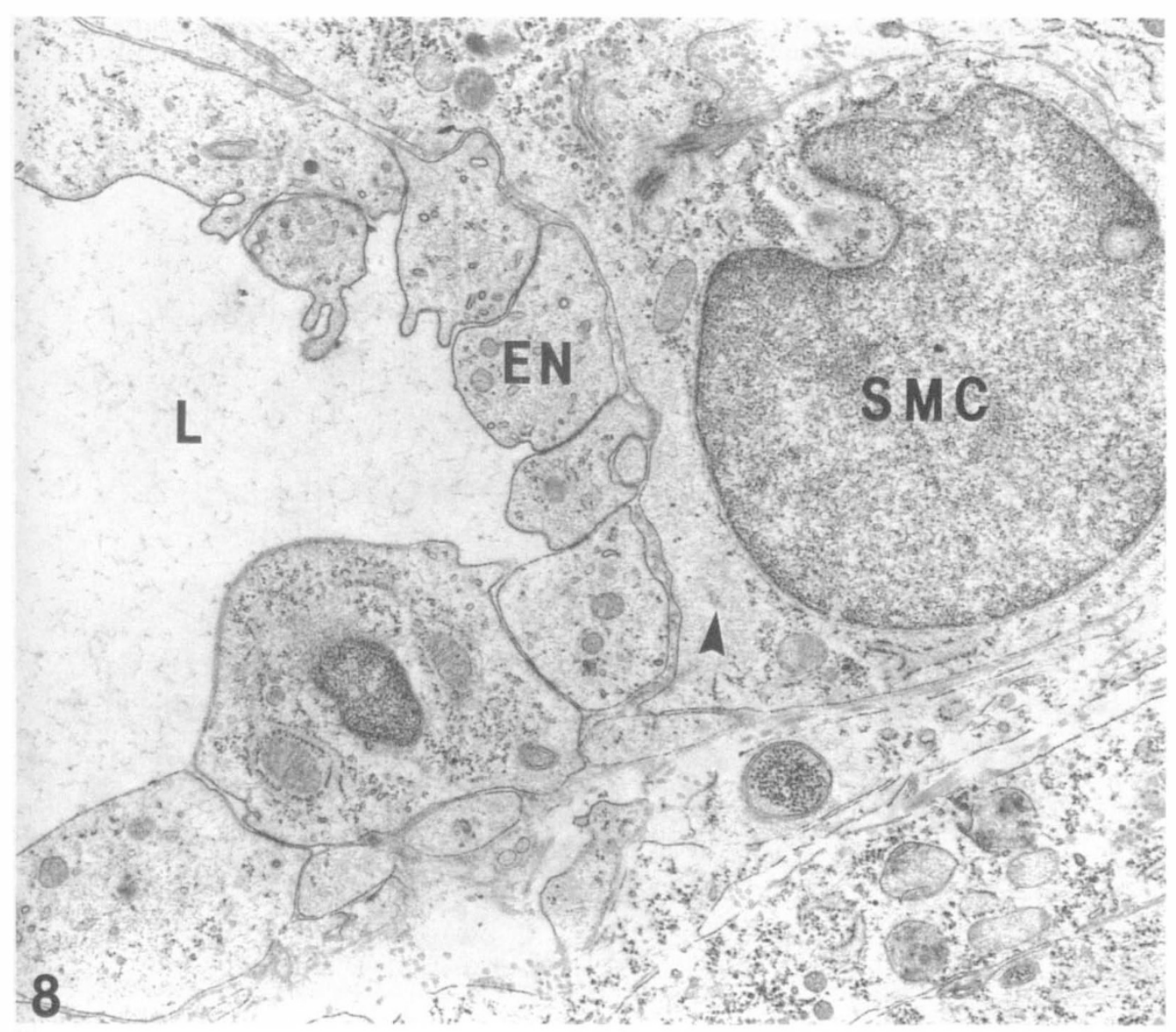

Fig. 8. Week 12. Part of an arteriole located in the region of the scleral condensation directly adjacent to the optic nerve entrance. Arrow head: dense body. EN, endothelial cell; L, lumen; SMC, smooth muscle cell. $(\times 18100)$

obvious in the 15 th week (Fig. 2) when, for the first time, arterioles and venules can be seen localised more anteriorly outside the choriocapillary layer. Ultrastructurally, they do not differ from those described in the adult eye $\left.\mathrm{e}^{1,9,10}\right)$, but they are not large at first. This is in contrast to the observations made by Mann," who described large (Haller's) vessels at the beginning of choroid development, whereas Barber ${ }^{12}$ observed a continuous increase in vessel diameter until it reached the adult size. From a general developmental point of view, Barber's description makes more sense, since vessels grow in diameter during embryogenesis.

It takes until the 22nd week before arteries and veins become observable for the first time (Fig. 3,9). They only differ from arterioles by exhibiting a continuous layer of smooth muscle cells, which are often followed by a second, intermittant one. In the subendothelial space, patches of a highly electron-dense material are found which most probably represent an early stage in the formation of an internal elastic lamina. Together with this immature internal elastic lamina, the occurence of glycogen in the smooth muscle cells permit the choroidal arteries of the $22 \mathrm{nd}$ week to be distinguished from those of the adult eye.

From the description made above, it becomes clear that both choroidal vascular 


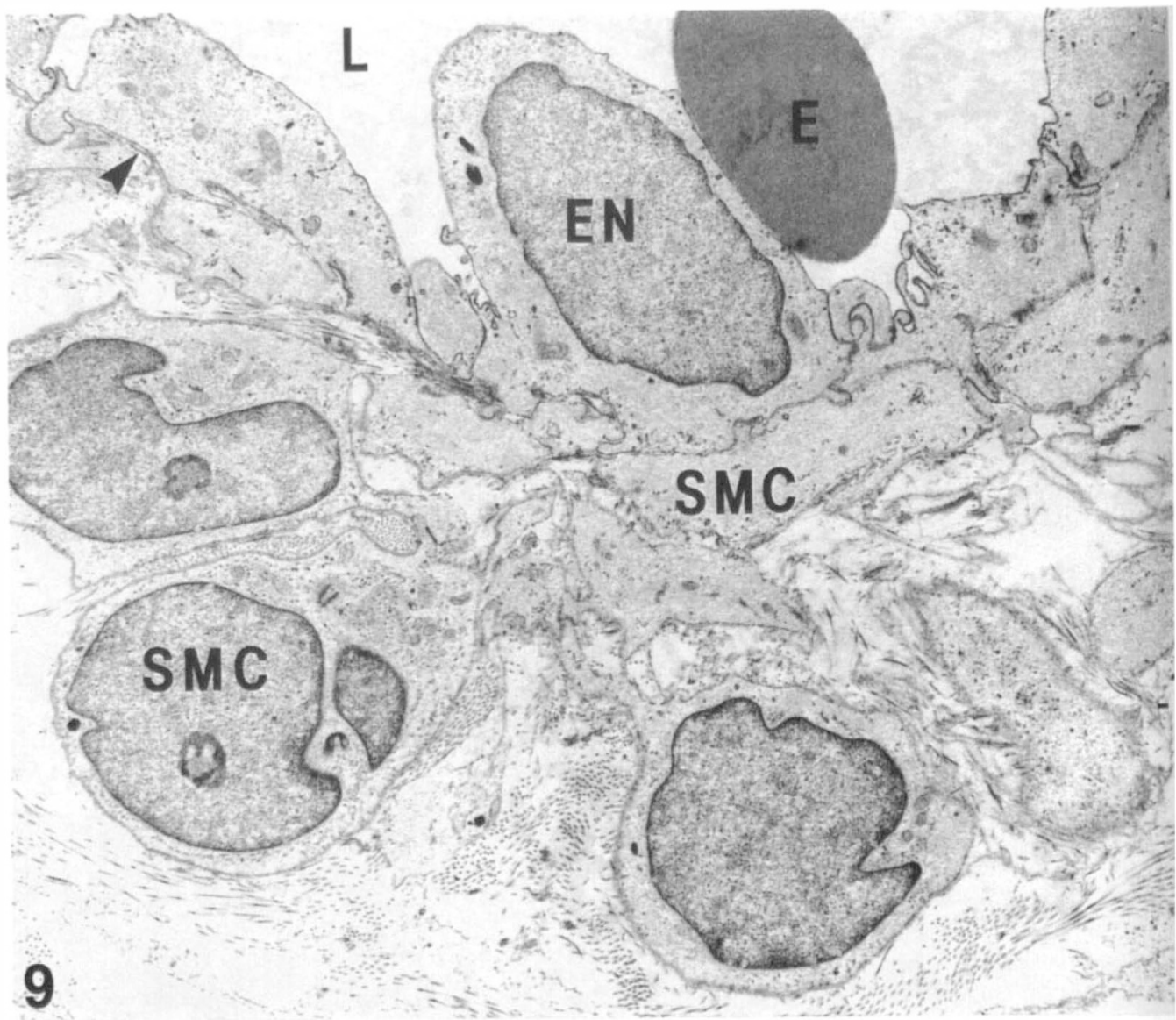

Fig. 9. Week 22. Choroidal artery. Arrowhead: lamina elastic interna. E, erythrocyte; EN, endothelial cell; L, lumen; SMC, smooth muscle cell. $(\times 4900)$.

(Haller's and Sattler's) layers exhibit arterial and venous vessels right from the time of their first appearance.

I would like to thank Ms. S. Pohl and Mr. A. Hermanowski for their excellent technical assistance. These studies were supported by grants Se 451/2-1 and Se 451/3-1 from Deutsche Forschungsgemeinschaft.

\section{References}

${ }^{1}$ Hogan MJ, Alvarado JA, Wedell JE: Histology of the human eye. Philadelphia. Saunders, 1971.

${ }^{2}$ Ozanics V and Jakobiec FA: Prenatal development of the eye and its adnexa. In Duane TD, Jaeger EA eds. Biomedical foundations of ophthalmology. Vol. 1. Philadelphia: Harper \& Row 1983, 1-86.

${ }^{3}$ Spitznas M: The fine structure of the chorioretinal border tissues of the adult human eye. Adv Ophthalmol 1974, 28: 78-174.
${ }^{4}$ Kelemen E, Janossa M, Calvo W, Flicdner TM: Developmental age estimated by bone-length measurement in human fetuses. Anat Rec 1984, 209: 547-52.

${ }^{5}$ Bertossi M, Roncali L: Ultrastructural changes of the developing blood vessels in the chick embryo adenohypophysis. J Subkicr Cytol 1981, 13: 391-406.

${ }^{6}$ Bauer KF and Vester G: Das clektronenmikroskopische Bild der Hirnkapillaren menschlicher Feten. Fortschr Neurol Psychiatr 1970, 38: 270-318.

${ }^{7}$ Mund ML, Rodrigues MM, Fine BS: Light and electron microscopic observations on the pigmented layers of the developing human cyc. Am J Ophthalmol 1972, 73: 167-82.

${ }^{8}$ Ozanics V, Raborn ME, Sagun D: Observations on the ultrastructure of the primate choroid coat. Exp Eye Res 1978, 26: 25-45.

${ }^{9}$ Hogan MJ and Fecney L: Electron microscopy of the human choroid. III. The blood vessels. Am J Ophthalmol 1961, 51: 1084-97. 
- Torcynznski E: Choroid and suprachoroid. In Jakobiec FA ed. Ocular anatomy, embryology, and teratology. Philadelphia: Harper \& Row 1982: 553-85.
${ }^{11}$ Mann I: The development of the human eye. 3rd ed. New York. Grune \& Stratton 1964.

${ }^{12}$ Barber AN: Embryology of the human eye. St. Louis. CV Mosby 1955. 